\title{
Should High-grade Extraosseous Osteosarcoma Be Treated With Multimodality Therapy Like Other Soft Tissue Sarcomas?
}

\author{
Zhengfu Fan MD, PhD, Shreyaskumar Patel MD, Valerae O. Lewis MD, \\ B. Ashleigh Guadagnolo MD, Patrick P. Lin MD
}

Received: 16 January 2015/ Accepted: 10 July 2015/Published online: 22 July 2015

(C) The Association of Bone and Joint Surgeons (B) 2015

\begin{abstract}
Background Extraosseous osteosarcoma is rare, and the most appropriate therapy is unclear because there are few studies regarding its treatment. The effectiveness of radiation and chemotherapy remains uncertain owing to conflicting results in previous reports.

Questions/purposes To review our experience with contemporary multimodality treatment, we asked: (1) What is the disease-specific survival and local relapse-free survival? (2) Does American Joint Commission on Cancer (AJCC) stage, tumor size, or location relate to disease outcome? (3) Does radiation therapy improve local control or survival? (4) Do doxorubicin and ifosfamide improve local control or survival?

Methods Between 1990 and 2012, we treated 40 patients for localized, high-grade extraosseous osteosarcoma. In this retrospective study, we could determine the status of
\end{abstract}

One of the authors certifies that he (SP), or a member of his or her immediate family, has or may receive payments or benefits, during the study period, an amount of less than USD 10,000 from CytRx (Los Angeles, CA, USA), an amount of less than 10,000 USD from Janssen Pharmaceuticals/Johnson \& Johnson (Titusville, NJ, USA), and an amount of USD 10,000-USD 100,000 from Novartis (Basel, Switzerland).

All ICMJE Conflict of Interest Forms for authors and Clinical Orthopaedics and Related Research ${ }^{\mathbb{R}}$ editors and board

members are on file with the publication and can be viewed on request.

Clinical Orthopaedics and Related Research ${ }^{\mathbb{R}}$ neither advocates nor endorses the use of any treatment, drug, or device.

Readers are encouraged to always seek additional information, including FDA-approval status, of any drug or device prior to clinical use.

Each author certifies that his or her institution approved the human protocol for this investigation, that all investigations were conducted in conformity with ethical principles of research, and that informed consent for participation in the study was obtained.
36 patients (90\%) either to death or for a minimum of 24 months of followup; four (10\%) were lost to followup before 24 months. There were 11 patients with AJCC Stage IIA and 25 with Stage III disease. All patients underwent wide surgical excision. Of the patients with Stage IIA disease, four received radiation and none received chemotherapy. Of the patients with Stage III disease, six received radiation, seven were treated with chemotherapy, and six received radiation and chemotherapy. During the study period, high-dose doxorubicin and ifosfamide was the preferred chemotherapy regimen for patients younger than 60 years with normal cardiac and renal function. Local relapse-free survival and disease-specific survival were determined by Kaplan-Meier analysis using a prospectively maintained institutional database supplemented by information from the institutional tumor registry. The Cox proportional hazard model was used to determine the effect of various factors on local recurrence and patient survival.

This study was performed at the University of Texas MD Anderson Cancer Center, Houston, TX, USA.

\section{Z. Fan}

Department of Orthopaedic Oncology, Peking University Cancer Hospital \& Institute, Beijing, China

\section{S. Patel}

Department of Sarcoma Medical Oncology, University of Texas MD Anderson Cancer Center, Houston, TX, USA

V. O. Lewis, P. P. Lin ( $\square)$

Department of Orthopaedic Oncology, University of Texas MD Anderson Cancer Center, 1515 Holcombe Boulevard, Unit 1448, Houston, TX 77030, USA

e-mail: plin@mdanderson.org

\section{B. A. Guadagnolo}

Department of Radiation Oncology, University of Texas MD Anderson Cancer Center, Houston, TX, USA 
Results At 5 years, local relapse-free survival was $47 \%$ (95\% CI, 27\%-64\%), and disease-specific survival was $53 \%$ (95\% CI, 35\%-68\%). In multivariate analysis, AJCC stage, which depends on tumor size, was the strongest predictor of local relapse-free survival (hazard ratio [HR] = $0.17, p=0.02$ ), while tumor depth was the best predictor of disease-specific survival $(\mathrm{HR}=5.6, \mathrm{p}=0.02)$. Radiation improved local relapse-free survival $(\mathrm{HR}=0.30, \mathrm{p}=0.03)$ but not disease-specific survival in multivariate analysis. A regimen of doxorubicin and ifosfamide was associated with better local relapse-free survival for patients with Stage III disease $(\mathrm{HR}=0.16, \mathrm{p}=0.04)$ but not disease-specific survival $(\mathrm{HR}=0.32, \mathrm{p}=0.08)$.

Conclusions With the limited number of patients in our study, it appears that extraosseous osteosarcoma behaves differently than osteosarcoma of bone. Multimodality treatment that includes doxorubicin and ifosfamide-based chemotherapy, radiation, and surgery may be a valid therapeutic strategy for Stage III disease, but larger, prospective studies will be needed to verify our preliminary observations.

Level of Evidence Level III, therapeutic study.

\section{Introduction}

Extraosseous osteosarcoma is a rare sarcoma with clinicopathologic features that are distinctively different from conventional osteosarcoma of bone [1,23]. Some of the differences are that the disease tends to affect older patients rather than adolescents, and the location of the tumor is dispersed widely throughout the body, rather than having a predilection for the distal femur and proximal tibia.

There are some studies pertaining to the treatment of extraosseous osteosarcoma $[1,11,14,15,20,23,24]$. The prognosis seems to vary among studies, and the optimal treatment strategy has yet to be defined. One possible reason for the disparity in results is that previous analyses tended to include different stages of disease. Although extraosseous osteosarcoma is usually a high-grade tumor, examples of low-grade disease have been described [22], and inclusion of such patients can be a confounding factor. Furthermore, if a study does not stratify patients on the basis of tumor size, yet another important prognostic factor may be overlooked [3]. However, not all studies have found size to be predictive of outcome [14].

The role of radiation is not universally agreed on because radiation is not used in the treatment of conventional osteosarcoma of bone. There has been greater emphasis on multimodality treatment that includes radiation and high-dose chemotherapy in addition to surgical resection [11, 14]. However, the numbers of patients in these studies are small, and the effectiveness of multimodality treatment remains in question. Previous studies suggested that extraosseous osteosarcoma was resistant to the chemotherapeutic regimens used, which may relate to using cisplatin-based protocols for conventional osteosarcoma of bone $[1,20]$. Some authors have advocated using soft tissue sarcoma strategies such as highdose doxorubicin and ifosfamide to improve the outcomes of patients with extraosseous osteosarcoma [1].

The purpose of our study is to review our more recent experience with contemporary multimodality treatment that includes doxorubicin and ifosfamide chemotherapy for localized, high-grade extraosseous osteosarcoma. We asked: (1) What are the disease-specific survival and local relapse-free survival for patients with extraosseous osteosarcoma? (2) Does American Joint Commission on Cancer (AJCC) stage, tumor size, or location relate to disease outcome in patients with extraosseous osteosarcoma? (3) Does the use of radiation therapy as an adjuvant improve local control or survival in patients with extraosseous osteosarcoma? (4) Do patients with doxorubicin and ifosfamide regimens have improved local relapse-free survival and disease-specific survival compared with patients treated without high-dose chemotherapy?

\section{Patients and Methods}

Between 1990 and 2012, we treated 40 patients for localized, high-grade extraosseous osteosarcoma. In this retrospective study, we could determine the status of 36 patients (90\%) either to death or for a minimum of 24 months of followup; four (10\%) were lost to followup before 12 months. The criteria for the histologic diagnosis were based on previous descriptions [3,5]. All patients had high-grade extraosseous osteosarcoma by the classification system of Bane et al. [3]. The pathologic and histologic diagnoses were not independently reviewed again for this study, since the diagnoses were made in all cases by musculoskeletal pathologists (AGA, BAC, MTD, HLE, AJL, JMM, VP, AKR, WLW) at our institution specializing in sarcomas, including the senior author (AGA) of the study by Bane et al. [3].There were 11 patients with AJCC Stage IIA disease (high-grade tumors, $\leq 5 \mathrm{~cm}$ ) and 25 patients with AJCC Stage III disease (high-grade tumors, $>5 \mathrm{~cm}$ ) [8]. No patients had Stage IIB disease (intermediate grade tumors, $>5 \mathrm{~cm}$ ) (Table 1). The mean age of the patients was 59 years (range, $12-80$ years). The mean and median tumor sizes were 9.0 and $7.5 \mathrm{~cm}$, respectively (range, $1-23 \mathrm{~cm}$ ). The mean and median followups were 69 and 51 months, respectively (range, 5-231 months). Patients had to have a minimum followup of 24 months, unless they died of disease before 12 months. The study was approved by and performed in accordance with our institutional review board. 
Table 1. Demographic data

\begin{tabular}{|c|c|c|}
\hline Variable & Number & Percent \\
\hline \multicolumn{3}{|l|}{ Gender } \\
\hline Female & 10 & 28 \\
\hline Male & 26 & 72 \\
\hline \multicolumn{3}{|l|}{ Race } \\
\hline Asian & 2 & 6 \\
\hline Black & 3 & 8 \\
\hline White & 28 & 78 \\
\hline Hispanic & 3 & 8 \\
\hline \multicolumn{3}{|l|}{ Site } \\
\hline Lower extremity & 21 & 58 \\
\hline Upper extremity & 8 & 22 \\
\hline Trunk & 6 & 17 \\
\hline Head and neck & 1 & 3 \\
\hline \multicolumn{3}{|l|}{ AJCC stage } \\
\hline IIA & 11 & 31 \\
\hline III & 25 & 69 \\
\hline \multicolumn{3}{|l|}{ Depth } \\
\hline Superficial & 12 & 33 \\
\hline Deep & 24 & 67 \\
\hline \multicolumn{3}{|l|}{ Surgical margin } \\
\hline R0 & 30 & 83 \\
\hline R1 & 6 & 17 \\
\hline \multicolumn{3}{|l|}{ Chemotherapy } \\
\hline No & 23 & 64 \\
\hline Yes & 13 & 36 \\
\hline \multicolumn{3}{|l|}{ Radiation } \\
\hline Yes & 16 & 44 \\
\hline No & 20 & 56 \\
\hline
\end{tabular}

AJCC = American Joint Commission on Cancer; R0 = complete resection with negative margins; $\mathrm{R} 1=$ removal of all macroscopic disease but with microscopically positive margins.

All patients underwent surgical resection with 30 margins classified as R0 (complete resection with negative margins) and six as R1 (removal of all macroscopic disease but with microscopically positive margins) $[12,25]$. Of the 11 patients with Stage IIA disease, seven were treated with surgery only, and four were treated with surgery and radiation. No patient received chemotherapy in this group (Table 2). Of the 25 patients with Stage III disease, chemotherapy, radiation, or both were used with surgery (Table 2).

For the 16 patients receiving radiation therapy, nine underwent preoperative treatment (mean dose, 50 Gy; range, 44-55 Gy), and seven underwent postoperative treatment (mean dose, $61 \mathrm{~Gy}$; range, 50-68 Gy). During the study period, radiation was considered for tumors near critical structures, such as major nerves and blood vessels, and also for positive margins. Three patients with positive
Table 2. Treatment groups

\begin{tabular}{|c|c|c|c|c|}
\hline $\begin{array}{l}\text { AJCC } \\
\text { stage }\end{array}$ & Group & Treatment & Number & Percen \\
\hline \multirow[t]{3}{*}{ IIA* } & & Surgery + radiation & 4 & 36 \\
\hline & & Surgery & 7 & 64 \\
\hline & & Subtotal & 11 & 100 \\
\hline \multirow[t]{5}{*}{ III } & A & $\begin{array}{l}\text { Surgery }+ \text { radiation }+ \\
\text { chemotherapy }\end{array}$ & 6 & 24 \\
\hline & & Surgery + chemotherapy & 7 & 28 \\
\hline & B & Surgery + radiation & 6 & 24 \\
\hline & & Surgery & 6 & 24 \\
\hline & & Subtotal & 25 & 100 \\
\hline
\end{tabular}

AJCC $=$ American Joint Commission on Cancer; $*$ patients with Stage IIA disease did not receive chemotherapy and therefore were not divided in groups for analysis of chemotherapy effect.

margins received postoperative radiation. There was not a strict criterion on the basis of size for radiation in this disease.

Patients with Stage III disease were divided in two groups on the basis of chemotherapy. Group A consisted of 13 patients who received chemotherapy. During the study period, we generally favored using six cycles of doxorubicin $\left(75 \mathrm{mg} / \mathrm{m}^{2}\right)$ and ifosfamide $\left(10 \mathrm{~g} / \mathrm{m}^{2}\right)$ for tumors greater than $5 \mathrm{~cm}$ in patients younger than 60 years with normal cardiac and renal function. Patients older than 60 years sometimes were considered for chemotherapy if they had few comorbidities. Of the 13 patients receiving chemotherapy, eight were able to complete at least four cycles of doxorubicin and ifosfamide. The other five had abbreviated courses or were switched to other less toxic regimens because of poor tolerance, including dacarbazine, methotrexate, cisplatin, gemcitabine, and taxotere. The analysis in this study was based on intent to treat so that the 13 patients (Group A) were grouped together regardless of the number of cycles of doxorubicin and ifosfamide. Two patients received methotrexate $\left(10-12 \mathrm{~g} / \mathrm{m}^{2}\right)$ and cisplatin $\left(120 \mathrm{mg} / \mathrm{m}^{2}\right)$ in addition to doxorubicin and ifosfamide. Group B consisted of patients who received no chemotherapy (12 patients). All chemotherapy drugs were FDA-approved medications.

We used Kaplan-Meier survival analysis to evaluate local relapse-free survival and disease-specific survival using a prospectively maintained institutional database supplemented by information from the institutional tumor registry and clinic notes from the most recent patient visits. Local relapse-free survival was defined as the time from surgery to local recurrence and disease-specific survival as the time from surgery to death if it was related to the primary disease (extraosseous osteosarcoma). Patients were censored at the last followup if the event did not occur. The log-rank test was used to evaluate differences in survival 
rates between subgroups. The Cox proportional hazard model was used to determine the effect of the treatments (chemotherapy and radiation) and patient factors on survival distribution using multicovariate analyses. The hazard ratios (HRs) with their 95\% CIs and the $\mathrm{p}$ values were determined. All tests were two-sided. Probability values less than 0.05 were considered statistically significant. Statistical analyses were conducted with SAS $^{\circledR}$ (Version 9.1; SAS Institute Inc, Cary, NC, USA), S-plus ${ }^{\circledR}$ (Version 8.0; TIBCO Software Inc, Palo Alto, CA, USA), or IBM SPSS ${ }^{\circledR}$ (Version 21; IBM Corporation, Armonk, NY, USA) statistical software.

\section{Results}

\section{Survival and Local Recurrence}

For the entire cohort of 36 patients with high-grade, localized extraosseous osteosarcoma, disease-specific survival was $53 \%$ at 5 years $(95 \% \mathrm{CI}, 35 \%-68 \%$; range, 5232 months; mean, 117 months; median, 62 months) (Fig. 1). At last followup, 13 of 36 patients were still alive with a disease-specific survival of $41 \%$ at 7 to 23 years (95\% CI, 23\%-58\%) (Fig. 1). Nineteen patients died of extraosseous osteosarcoma, whereas four died of unrelated causes. Local recurrence developed in 18 of 36 patients. At 5 years local relapse-free survival was $47 \%$ (95\% CI, $27 \%$ 64\%; range, 3-232 months; mean, 89 months; median, 59 months) (Fig. 2). At last followup, local recurrence-free survival was $40 \%$ at 6 to 14 years $(95 \%$ CI, 20\%-60\%) (Fig 2). Four patients were treated for multiple local recurrences. All four had Stage III disease. One of the four had an R1 resection of the primary tumor (pelvic site of disease) whereas the others had R0 resection (sites of disease in thigh and knee). Three of the patients died of

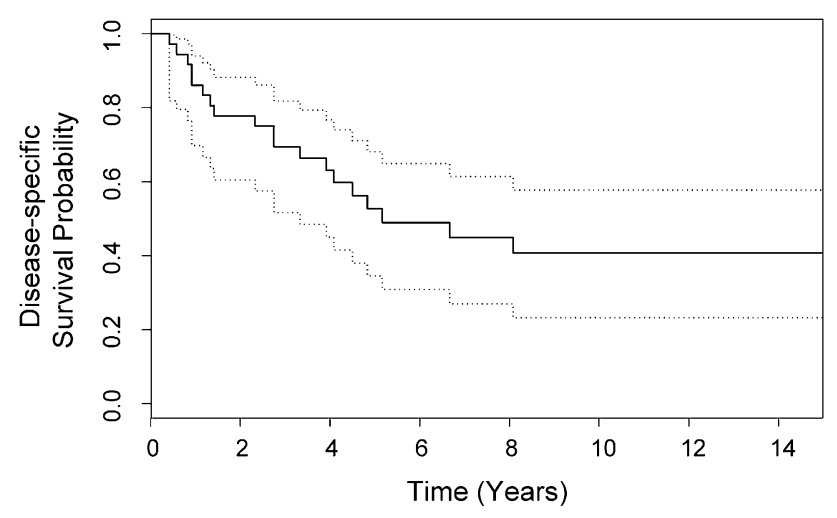

Fig. 1 Disease-specific survival for the entire cohort of 36 patients is shown with $95 \%$ CIs (dotted lines). At 5 years disease-specific survival was $53 \%(95 \%$ CI, 35\%-68\%). disease with a mean disease-specific survival of 65 months (range, 47-97 months).

\section{AJCC Stage, Tumor Size, and Location}

AJCC stage, tumor size, and depth were found to be important predictors of outcome, but location (central vs extremity) did not affect local recurrence or survival. Stage of disease in the current study depends on size, with Stage IIA tumors being $5 \mathrm{~cm}$ or smaller and Stage III tumors larger than $5 \mathrm{~cm}$. In multivariate analysis, the AJCC soft tissue sarcoma stage was the strongest predictor of local relapse-free survival (HR $=0.17 ; 95 \% \mathrm{CI}, 0.04-0.78 ; \mathrm{p}=$ $0.02)$ (Table 3). Two of $11(18 \%)$ patients with Stage IIA $(\leq 5 \mathrm{~cm})$ disease had local recurrence, whereas 16 of 25 $(64 \%)$ patients with Stage III $(>5 \mathrm{~cm})$ disease had local recurrence. Tumor depth was the only independent predictor of disease-specific survival in multivariate analysis $(\mathrm{HR}=5.6 ; 95 \% \mathrm{CI}, 1.3-24.3 ; \mathrm{p}=0.02)$. Tumor depth was found to be associated with stage of disease by chi-square analysis, with most superficial tumors being Stage IIA and most deep tumors being Stage III $(\mathrm{p}<0.001)$ (Table 4). At 5 years the disease-specific survival was $76 \%(95 \% \mathrm{CI}$, $47 \%-100 \%$ ) for Stage IIA and $43 \%$ (95\% CI, 23\%-62\%) for Stage III ( $\log$ rank test, $\mathrm{p}=0.02)$. The site of disease

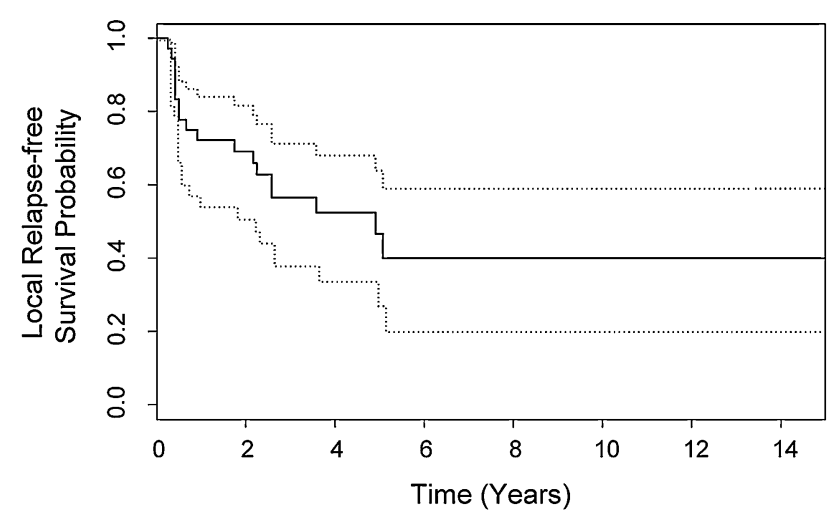

Fig. 2 Local relapse-free survival for the entire cohort of 36 patients is shown with $95 \%$ CIs (dotted lines). At 5 years local relapse-free survival was $47 \%$ (95\% CI, 27\%-64\%).

Table 3. Multivariate analysis of local relapse-free survival for all patients

\begin{tabular}{llll}
\hline Factor & Hazard ratio & $95 \%$ CI & p value \\
\hline AJCC Stage (IIA) & 0.17 & $0.04-0.78$ & 0.02 \\
Radiation & 0.30 & $0.11-0.87$ & 0.03 \\
Surgical margin (R0) & 0.37 & $0.12-1.12$ & 0.08 \\
\hline
\end{tabular}

AJCC $=$ American Joint Commission on Cancer; R0 = complete resection with negative margins. 
Table 4. Chi-square analysis of depth and stage

\begin{tabular}{lccc}
\hline AJCC stage & Depth & Total \\
\cline { 2 - 3 } & Deep & Superficial & \\
\hline IIA & 2 & 9 & 11 \\
III & 22 & 3 & 25 \\
Total & 24 & 12 & 36 \\
\hline
\end{tabular}

$\mathrm{AJCC}=$ American Joint Commission on Cancer; $\mathrm{p}<0.001$.

Table 5. Multivariate analysis of local relapse-free survival for patients with Stage III disease

\begin{tabular}{llll}
\hline Factor & Hazard ratio & $95 \%$ CI & p value \\
\hline Radiation & 0.08 & $0.016-0.42$ & 0.003 \\
Surgical margin (R0) & 0.09 & $0.014-0.60$ & 0.012 \\
Chemotherapy & 0.16 & $0.028-0.88$ & 0.035 \\
Sex (female) & 0.20 & $0.040-0.96$ & 0.045 \\
\hline
\end{tabular}

$\mathrm{R} 0=$ complete resection with negative margins.

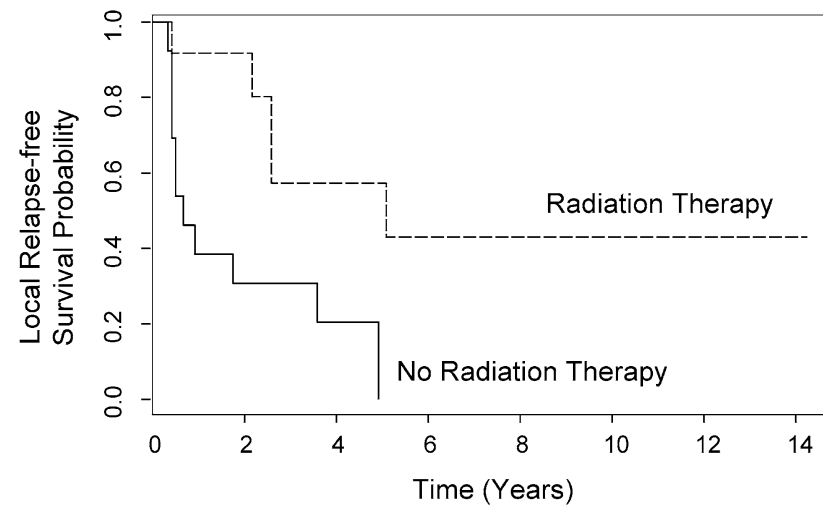

Fig. 3 Radiation therapy was the strongest predictor for local relapse in Stage III disease in multivariate analysis. Kaplan-Meier analysis (univariate) showed that patients receiving radiation had 4- and 5-year local relapse-free survival rates of $57 \%$ (95\% CI, 33\%-100\%) for both years while patients not receiving radiation had 4- and 5-year local relapse-free survival rates of $21 \%(95 \% \mathrm{CI}, 7 \%-64 \%)$ and $0 \%$ (95\% CI not derivable), respectively (log-rank test, $\mathrm{p}=0.01$ ).

(extremity vs central) did not predict local recurrence or survival in multivariate analysis.

\section{Radiation Therapy}

In a Cox proportional hazard model, radiation was associated with superior local relapse-free survival for all patients $(\mathrm{HR}=0.30 ; 95 \% \mathrm{CI}, 0.11-0.87 ; \mathrm{p}=0.03)$ (Table 3), and for patients with Stage III disease, radiation was the strongest predictor for local relapse (Table 5). For these patients, local relapse-free survival at 5 years was $57 \%$ for patients receiving radiation and $0 \%$ for patients not treated with radiation (Fig. 3). Three of six patients
(50\%) with positive margins ( $\mathrm{R} 1$ resection) received postoperative radiation. Surgical margin was also a predictor of local relapse-free survival for patients with Stage III disease $(\mathrm{HR}=0.09 ; 95 \% \mathrm{CI}, 0.14-0.60 ; \mathrm{p}=0.01)$ (Table 5). In multivariate analysis, radiation was not associated with better disease-specific survival $(\mathrm{HR}=0.69$; 95\% CI, 0.24-1.9; $\mathrm{p}=0.48$ ).

\section{Chemotherapy}

Because none of the patients with Stage IIA disease were treated with chemotherapy, and yet had superior local relapse-free survival and disease-specific survival, a subset analysis was performed for the 25 patients with Stage III disease to determine whether chemotherapy might have an effect on outcome. Multivariate analysis for local relapsefree survival showed that the strongest predictor was radiation, followed by surgical margin, chemotherapy (Group A vs Group B), and sex (Table 5). In multivariate analysis for disease-specific survival of patients with Stage III disease, the final covariate in the model was chemotherapy with doxorubicin and ifosfamide, but this did not reach statistical significance $(\mathrm{HR}=0.32 ; 95 \% \mathrm{CI}$, 0.09-1.12; $\mathrm{p}=0.08$ ). Consequently, the model did not converge, and none of the factors in our analysis were considered predictors of disease-specific survival for patients with Stage III disease. Our analysis did include the combination of radiation and chemotherapy, which was not found to be an independent covariate for either local relapse-free survival or disease-free survival. In addition, patients who received chemotherapy (Group A) had a mean age of 50 years whereas patients who did not have chemotherapy (Group B) had a mean age of 71 years (Student's t-test, $\mathrm{p}=0.01$ ). However, age was not a predictive factor for local recurrence or survival in multivariate analysis.

\section{Discussion}

Uncertainty still exists regarding the role of chemotherapy and radiation therapy in the treatment of extraosseous osteosarcoma. Part of the reason for this is that extraosseous osteosarcoma encompasses a wide spectrum of disease. Owing to the rarity of the disease and lack of prospective trials specific to this disease, previous studies have not always separated patients with small $(<5 \mathrm{~cm})$ tumors and low-grade histologic features from patients with large, high-grade tumors $[1,11,14,20]$. We found a high rate of local recurrence and poor survival, especially for patients with Stage III disease. The parameters for soft tissue sarcoma staging, including depth and size, were 
predictive factors for local recurrence and disease-specific survival, supporting the notion that extraosseous osteosarcoma behaves like soft tissue sarcomas. Radiation had a positive effect on local control but not disease-specific survival. Chemotherapy in the form of doxorubicin and ifosfamide had a positive effect on local relapse-free survival for patients with Stage III disease, but not on diseasespecific survival.

There were several limitations to our study. It was a retrospective analysis of patients treated in various ways. We had low numbers of patients despite this being one of the largest studies reported. The patient population was heterogeneous and various treatments were offered to patients. The criteria for chemotherapy and radiation were not prospectively defined and used during the study period. There was evidence for a degree of selection bias in terms of patients who were selected for chemotherapy. The mean age was significantly older for patients with Stage III disease treated without chemotherapy. This is not surprising since doxorubicin and ifosfamide were not routinely given to patients older than 60 years. However, age alone was not a predictive factor for local recurrence or disease-specific patient survival in our multivariate analysis. Selection bias also may have been present for radiation, and patients perceived to have a worse prognosis may have been selectively targeted for radiation. This potentially would diminish the measured benefit of radiation in local relapsefree survival and disease-specific survival. Loss of followup is an issue, despite there being only four patients $(10 \%)$ who were excluded on the basis of inadequate followup, because this is a small cohort and loss of even a few patients could be important.

The results of our study confirm the impression that high-grade extraosseous osteosarcoma is an aggressive disease as evidenced by a local relapse-free survival of $47 \%$ and a disease-specific survival of $53 \%$ at 5 years. Previous authors have commented on the poor prognosis of the disease [14]. Ahmad et al. [1] reported a 46\% 5-year disease-specific survival rate in 30 patients, and McCarter et al. [17] reported a 50\% 5-year disease-specific survival rate in 15 patients.

Our results support the view that the parameters for current AJCC staging of soft tissue sarcomas, which include size and depth, are relevant to the prognosis of extraosseous osteosarcoma. As our study was limited to high-grade, localized tumors, there were only two stages (IIA and III) to which our patients belonged. The separation between these two stages was size, based on a $5 \mathrm{~cm}$ cut-off. Our multivariate analysis validated this separation and showed that the AJCC stage, as defined by the $5 \mathrm{~cm}$ cut-off, was the best predictor of local recurrence. For disease-specific survival, depth of tumor, as opposed to stage, proved to be a better predictor of outcome. In our cohort, depth was associated with stage, with most of the superficial tumors being Stage IIA and most of the deep tumors being Stage III $(\mathrm{p}<0.001)$. The patients with Stage IIA disease $(\leq 5 \mathrm{~cm}$ tumors) had a 5 -year disease-specific survival of $76 \%$ while the patients with Stage III disease $(>5 \mathrm{~cm})$ had survival of $43 \%$ (p = 0.02 ). Previous authors have not agreed on whether tumor size is predictive of outcome, and some have stated that size does not matter since small tumors can behave aggressively [14], whereas others found size to affect prognosis [3]. In the study by Lee et al. [14], five of seven patients with tumors smaller than $5 \mathrm{~cm}$ died of disease. In contrast to their results, Bane et al. [3] reported that all six patients who were alive without disease at last followup had tumors smaller than $5 \mathrm{~cm}$. In our study, we found that small tumors were locally aggressive with a relatively high local recurrence rate $(18 \%)$ but were less likely to metastasize and cause death. Consideration may be given to selective treatment of tumors smaller than $5 \mathrm{~cm}$ with radiation, especially in unfavorable anatomic locations where wide margins are difficult to obtain (such as the popliteal fossa, the hand, and foot) or if margins are compromised. We did not find that location was predictive of local recurrence or patient survival, but there were relatively few cases (seven) in central locations, making it difficult to detect a small effect for this factor. We did find that surgical margin predicted local recurrence for patients with Stage III disease. In our series three of six patients received postoperative radiation owing to a positive margin. It is unclear from this retrospective analysis why the other three patients did not receive radiation. Our results suggest that margin status may need to be considered more carefully regarding the decision for radiation.

In multivariate analysis, radiation treatment was an independent predictor for local relapse-free survival. The poor prognosis for tumors larger than $5 \mathrm{~cm}$ justifies close examination of multimodality treatment as a therapeutic strategy. In the past our clinicians thought that radiation therapy might not be useful for extraosseous osteosarcoma because conventional osteosarcoma of bone is relatively radioresistant, and radiation is not a standard part of treatment for conventional osteosarcoma [2]. However, the use of radiation for extraosseous osteosarcoma has been recommended [23]. The positive effect of radiation may be one reason why extraosseous osteosarcoma should be regarded a disease distinct from primary conventional osteosarcoma of bone. Furthermore, the late age of onset and the strong dependence of survival on tumor size also suggest differences between the diseases.

Chemotherapy in the form of high-dose doxorubicin and ifosfamide was found to have a positive effect on local recurrence for patients with Stage III disease in multivariate analysis but not on disease-specific survival. Despite chemotherapy being the last covariate remaining in 
the multiple regression analysis for disease-specific survival, it was not significant $(\mathrm{p}=0.08)$. The reasons for this may be either that there were not enough patients to show a modest difference or that there was no true effect on disease-specific survival. The fact that doxorubicin and ifosfamide were predictive of local relapse-free survival in patients with Stage III disease is suggestive of its having some efficacy. More work, ideally in the setting of a prospective trial, would be needed to address the question of the exact oncologic benefit of doxorubicin and ifosfamide for this disease. Our results are consistent with the view that extraosseous osteosarcoma should still be considered a relatively chemoresistant disease. Previous studies have suggested that extraosseous osteosarcoma is not especially sensitive to chemotherapy $[17,20]$. The study by Ahmad et al. [1] indicated that there were poor radiographic and histologic responses of tumors to doxorubicin-based chemotherapy of various combinations, which in most cases (19 of 27) was given without ifosfamide. In their cohort of 27 patients, $19 \%$ had an objective response to treatment; $48 \%$ had progressive disease and $33 \%$ stable disease during treatment [1]. However, some authors suggest a possible effect of chemotherapy on clinical outcomes [11, 24]. In the study by GoldsteinJackson et al. [11], 17 patients were treated with conventional osteosarcoma chemotherapy, which included doxorubicin, ifosfamide, cisplatin, and methotrexate. The 3 -year overall survival rate was $77 \%$, but five patients had tumors smaller than $5 \mathrm{~cm}$ [11]. In the study by Torigoe et al. [24], 15 patients received different forms of chemotherapy that included various combinations of doxorubicin, ifosfamide, etoposide, cisplatin, methotrexate, and carboplatin. A response rate of $45 \%$ and a 5 -year overall survival rate of $66 \%$ for patients with Stage III disease was reported [24]. In one European trial, adjuvant chemotherapy in the form of cyclophosphamide, vincristine, doxorubicin, and dacarbazine (CYVADIC) reduced local recurrence but not overall survival, similar to our study [4]. One theory regarding how chemotherapy might affect local control is that chemotherapy may affect actively dividing cells at the margins of tumors [19]. Although controversy remains regarding the topic with several articles failing to show an effect on local control [6, $7,18]$, other studies have shown that chemotherapy could benefit patients with sarcoma in terms of better local relapse-free survival and overall survival [9, 10, 13, 21]. The effects could be dependent on the exact agents and dosages. This may explain in part why some older chemotherapy combinations such as CYVADIC (cyclophosphamide, vincristine, doxorubicin, dacarbazine) might have less effect than high-dose doxorubicin and ifosfamide. In addition, these studies pertained to sarcomas in general and not to extraosseous osteosarcoma specifically. The effects of chemotherapy depend in large part on the particular histologic features of the disease [16].

We found that high-grade extraosseous osteosarcoma is an aggressive disease with a high rate of local and distant relapse, particularly for patients with Stage III disease. Despite the limited number of patients in our study and the heterogeneity of treatments, it appears that extraosseous osteosarcoma behaves differently from osteosarcoma of bone. It shares certain similarities with soft tissue sarcomas, in terms of late age of onset, prognostic factors, and response to radiation. Parameters that are important for AJCC staging of soft tissue tumors, including tumor size and depth, are important predictors of outcome and may be important in treatment decision-making. Patients with tumors $5 \mathrm{~cm}$ or smaller have better survival even in the absence of chemotherapy. Patients with high-grade tumors larger than $5 \mathrm{~cm}$ have a poor prognosis. Our data suggest that an aggressive combined multimodality therapeutic strategy that includes radiation, chemotherapy, and wide surgical resection may be beneficial for patients with Stage III disease, but larger prospective studies will be necessary to confirm these observations.

Acknowledgments We thank Wei Lien Wang MD (Department of Pathology, University of Texas MD Anderson Cancer Center), Barry W. Feig MD (Department of Surgical Oncology, University of Texas MD Anderson Cancer Center), Gunnar K. Zagars MD (Department of Radiation Oncology, University of Texas MD Anderson Cancer Center), Bryan S. Moon MD (Department of Orthopaedic Oncology, University of Texas MD Anderson Cancer Center), Robert L. Satcher $\mathrm{MD}, \mathrm{PhD}$ (Department of Orthopaedic Oncology, University of Texas MD Anderson Cancer Center), Justin E. Bird MD (Department of Orthopaedic Oncology, University of Texas MD Anderson Cancer Center), and Wenli Dong MS (Department of Biostatistics, University of Texas MD Anderson Cancer Center) for their valuable insights and input in this study. We also acknowledge the following for contributing to the histologic diagnosis of extraosseous osteosarcoma: Alberto G. Ayala MD (Department of Pathology and Genomic Medicine, Houston Methodist Hospital); Bogdan A. Czerniak MD $\mathrm{PhD}$ (Department of Pathology, University of Texas MD Anderson Cancer Center), Michael T. Deavers MD (Department of Pathology and Genomic Medicine, Houston Methodist Hospital); Harry L. Evans MD (Department of Pathology, University of Texas MD Anderson Cancer Center), Alexander J. Lazar MD PhD (Department of Pathology, University of Texas MD Anderson Cancer Center), Jeanne M. Meis MD (Department of Pathology, University of Texas MD Anderson Cancer Center), Victor Prieto MD PhD (Department of Pathology, University of Texas MD Anderson Cancer Center), and A. Kevin Raymond MD (retired from Department of Pathology, University of Texas MD Anderson Cancer Center).

\section{References}

1. Ahmad SA, Patel SR, Ballo MT, Baker TP, Yasko AW, Wang X, Feig BW, Hunt KK, Lin PP, Weber KL, Chen LL, Zagars GK, Pollock RE, Benjamin RS, Pisters PW. Extraosseous osteosarcoma: response to treatment and long-term outcome. $J$ Clin Oncol. 2002;20:521-527. 
2. Bacci G, Lari S. Current treatment of high grade osteosarcoma of the extremity: review. J Chemother. 2001;13:235-243.

3. Bane BL, Evans HL, Ro JY, Carrasco CH, Grignon DJ, Benjamin RS, Ayala AG. Extraskeletal osteosarcoma: a clinicopathologic review of 26 cases. Cancer. 1990;65:2762-2770.

4. Bramwell V, Rouesse J, Steward W, Santoro A, SchraffordtKoops H, Buesa J, Ruka W, Priario J, Wagener T, Burgers M, et al. Adjuvant CYVADIC chemotherapy for adult soft tissue sarcoma: reduced local recurrence but no improvement in survival: a study of the European Organization for Research and Treatment of Cancer Soft Tissue and Bone Sarcoma Group. J Clin Oncol. 1994;12:1137-1149.

5. Chung EB, Enzinger FM. Extraskeletal osteosarcoma. Cancer. 1987;60:1132-1142.

6. Cormier JN, Huang X, Xing Y, Thall PF, Wang X, Benjamin RS, Pollock RE, Antonescu CR, Maki RG, Brennan MF, Pisters PW. Cohort analysis of patients with localized, high-risk, extremity soft tissue sarcoma treated at two cancer centers: chemotherapyassociated outcomes. J Clin Oncol. 2004;22:4567-4574.

7. Dileo P, Demetri GD. Update on new diagnostic and therapeutic approaches for sarcomas. Clin Adv Hematol Oncol. 2005;3:781-791.

8. Edge SB, Byrd DR, Compton CC, Fritz AG, Greene FL, Trotti A, eds. AJCC Cancer Staging Manual. 7th ed. New York, NY: Springer; 2010.

9. Frustaci S, De Paoli A, Bidoli E, La Mura N, Berretta M, Buonadonna A, Boz G, Gherlinzoni F. Ifosfamide in the adjuvant therapy of soft tissue sarcomas. Oncology. 2003;65(suppl 2):80-84.

10. Frustaci S, Gherlinzoni F, De Paoli A, Bonetti M, Azzarelli A, Comandone A, Olmi P, Buonadonna A, Pignatti G, Barbieri E, Apice G, Zmerly H, Serraino D, Picci P. Adjuvant chemotherapy for adult soft tissue sarcomas of the extremities and girdles: results of the Italian randomized cooperative trial. J Clin Oncol. 2001;19:1238-1247.

11. Goldstein-Jackson SY, Gosheger G, Delling G, Berdel WE, Exner GU, Jundt G, Machatschek JN, Zoubek A, Jurgens H, Bielack SS; Cooperative Osteosarcoma Study Group COSS. Extraskeletal osteosarcoma has a favourable prognosis when treated like conventional osteosarcoma. J Cancer Res Clin Oncol. 2005;131:520-526.

12. Hermanek P, Wittekind C. Residual tumor (R) classification and prognosis. Semin Surg Oncol. 1994;10:12-20.

13. Italiano A, Penel N, Robin YM, Bui B, Le Cesne A, PipernoNeumann S, Tubiana-Hulin M, Bompas E, Chevreau C, Isambert
N, Leyvraz S, du Chatelard PP, Thyss A, Coindre JM, Blay JY. Neo/adjuvant chemotherapy does not improve outcome in resected primary synovial sarcoma: a study of the French Sarcoma Group. Ann Oncol. 2009;20:425-430.

14. Lee JS, Fetsch JF, Wasdhal DA, Lee BP, Pritchard DJ, Nascimento AG. A review of 40 patients with extraskeletal osteosarcoma. Cancer. 1995;76:2253-2259.

15. Lee S, Lee MR, Lee SJ, Ahn HK, Yi J, Yi SY, Seo SW, Sung KS, Park JO, Lee J. Extraosseous osteosarcoma: single institutional experience in Korea. Asia Pac J Clin Oncol. 2010;6:126-129.

16. Maki RG. Role of chemotherapy in patients with soft tissue sarcomas. Expert Rev Anticancer Ther. 2004;4:229-236.

17. McCarter MD, Lewis JJ, Antonescu CR, Brennan MF. Extraskeletal osteosarcoma: analysis of outcome of a rare neoplasm. Sarcoma. 2000;4:119-123.

18. Mocellin S, Rossi CR, Brandes A, Nitti D. Adult soft tissue sarcomas: conventional therapies and molecularly targeted approaches. Cancer Treat Rev. 2006;32:9-27.

19. O'Donnell PW, Manivel JC, Cheng EY, Clohisy DR. Chemotherapy influences the pseudocapsule composition in soft tissue sarcomas. Clin Orthop Relat Res. 2014;472:849-855.

20. Patel SR, Benjamin RS. Primary extraskeletal osteosarcoma: experience with chemotherapy. J Natl Cancer Inst. 1995;87: 1331-1333.

21. Pervaiz N, Colterjohn N, Farrokhyar F, Tozer R, Figueredo A, Ghert M. A systematic meta-analysis of randomized controlled trials of adjuvant chemotherapy for localized resectable soft-tissue sarcoma. Cancer. 2008;113:573-581.

22. Sabatier R, Bouvier C, de Pinieux G, Sarran A, Brenot-Rossi I, Pedeutour F, Chetaille B, Viens P, Weiller PJ, Bertucci F. Lowgrade extraskeletal osteosarcoma of the chest wall: case report and review of literature. BMC Cancer. 2010;10:645.

23. Sordillo PP, Hajdu SI, Magill GB, Golbey RB. Extraosseous osteogenic sarcoma: a review of 48 patients. Cancer. 1983;51: $727-734$

24. Torigoe T, Yazawa Y, Takagi T, Terakado A, Kurosawa H. Extraskeletal osteosarcoma in Japan: multiinstitutional study of 20 patients from the Japanese Musculoskeletal Oncology Group. J Orthop Sci. 2007;12:424-429.

25. UICC (International Union Against Cancer). TNM Classification of Malignant Tumours. In Hermanek P, Sobin LH, eds. Berlin, Germany: Springer-Verlag; 1987. 